\begin{tabular}{ll|l} 
Case Reports in & \multicolumn{2}{c}{ Case Rep Gastroenterol 2013;7:122-126 } \\
\cline { 2 - 3 } Gastroenterology & $\begin{array}{l}\text { DOI: 10.1159/000350320 } \\
\text { Published online: March 13, 2013 }\end{array}$ & $\begin{array}{l}\text { ○ 2013 S. Karger AG, Basel } \\
1662-0631 / 13 / 0071-0122 \$ 38.00 / 0 \\
\text { www.karger.com/crg }\end{array}$ \\
\hline & $\begin{array}{l}\text { This is an Open Access article licensed under the terms of the Creative Commons Attribution- } \\
\text { NonCommercial-NoDerivs 3.0 License (www.karger.com/OA-license), applicable to the } \\
\text { online version of the article only. Distribution for non-commercial purposes only. }\end{array}$
\end{tabular}

\title{
Effective Treatment of Intestinal Behçet's Disease with Long-Term, Low-Dose Clarithromycin
}

\author{
Yukiya Hakozaki Keiji Mitani Chizuko Okada Hisato Terada \\ Shinichi Kobari \\ Department of Internal Medicine, Japan Self Defense Forces Central Hospital, Tokyo, \\ Japan
}

\section{Key Words}

Intestinal Behçet's disease · Long-term, low-dose clarithromycin · Macrolide · Glucocorticoid

\begin{abstract}
A 51-year-old man was referred for body weight loss and lower right abdominal pain. Total colonoscopy revealed discrete and round ulceration at the ileocecal valve, and he was diagnosed with intestinal Behçet's disease (BD). By treatment with glucocorticoid, colchicine and salazosulfapyridine, the symptoms and ulceration were improved, but cessation of glucocorticoid resulted in relapse of ulceration at the terminal ileum. Long-term, low-dose treatment with clarithromycin (CAM) was implemented for chronic respiratory infections. Furthermore, we expected that this CAM treatment would also be effective in BD. During this long-term, low-dose treatment with CAM, discrete ulceration at the terminal ileum was never revealed by follow-up total colonoscopy once or twice per year for 7 years. No reports have described the effectiveness of this treatment in patients with intestinal BD; however, we confirm that long-term treatment with low-dose CAM might have clinical benefits for patients with intestinal BD.
\end{abstract}

\section{Introduction}

Gastrointestinal ulcerations occur in some patients with Behçet's disease (BD). In patients with intestinal BD, discrete and deep ulcerations are more often seen in the terminal ileum, cecum and ascending colon [1]. These deeply penetrating ulcers tend to perforate, requiring emergency surgical procedures, with high recurrence and re-operation rates in the long term. The essential cause of this disease is unknown. Compared with other autoimmune 
diseases, intestinal BD may represent aberrant immune activity triggered by exposure to an agent, perhaps infectious, in patients with a genetic predisposition to develop the disease [2]. There is no evidence-based treatment that can be recommended for the management of intestinal BD. Agents such as corticosteroids, azathioprine, thalidomide or TNF- $\alpha$ antagonists should be tried first before surgery, except in emergencies [3]. These agents are not used for a long period clinically because of their poor tolerability, potential for toxicity and high cost. Here, we describe a patient with intestinal BD who showed frequent relapse of discrete ulceration at the terminal ileum, which was improved by long-term, low-dose treatment with clarithromycin (CAM).

\section{Case Report}

A 51-year-old Japanese man had oral aphthous ulcers, genital ulcers on the scrotum and acneiform lesions in 1987. His symptoms repeatedly relapsed from 1987 to 1989. In August 1989, he was referred to our hospital for further examination due to body weight loss and lower right abdominal pain. Total colonoscopy revealed discrete and round ulceration at the ileocecal valve with moderate inflammation (fig. 1a). He had no ocular or neurological disease, but human lymphocyte antigens were positive for B51. We performed frequency colonoscopic biopsy specimens at the ulceration, but the formation of epithelioid cell granulomas was never detected. Crohn's disease was excepted from the histological examination and clinical symptoms, and according to these findings the patient was diagnosed as having intestinal BD. After admission, he was treated with glucocorticoid (prednisolone $30 \mathrm{mg} /$ day), colchicine and salazosulfapyridine in hospital. In 1997 drug-induced liver injury occurred because of azathioprine. The symptoms, including oral aphthous ulcers, were improved, and prednisolone dose was therefore decreased. After discharge, treatment of salazosulfapyridine (or mesalazine) was continued, but the discrete ulceration at the terminal ileum relapsed frequently once every 1 or 2 years from 1989 to 2004 (fig. 1b, c, fig. 2). Whenever the ulceration of the terminal ileum relapsed, the administration of prednisolone was needed.

In 2002, the patient had fever and hemoptysis, and chest CT showed irregular consolidation and ground-glass opacity in March 2003 (fig. 1d). Venous thrombosis was diagnosed due to $\mathrm{BD}$, and antimicrobial therapy and bronchial artery embolization improved these symptoms. In 2004, CAM (200 mg/day) was started for the treatment of chronic respiratory infections and maintained for about 7 years. Furthermore, we expected that this CAM treatment would also be effective in BD. During this long-term, low-dose treatment with CAM, the discrete ulceration of the terminal ileum was never revealed by follow-up total colonoscopy once or twice per year for 7 years (fig. 1e). However, the patient was repeatedly hospitalized for acute or chronic respiratory infections; nevertheless, despite the treatment with antimicrobial therapies, for example sultamicillin tosylate hydrate, piperacillin sodium, tazobactam or meropenem hydrate, his bacterial pneumonia gradually worsened, especially in 2009 and thereafter. He died due to respiratory failure in November 2011.

\section{Discussion}

BD is a multisystem inflammatory disease characterized by recurrent oral aphthous ulcers, genital ulcers, skin lesions and vascular and gastrointestinal disease. The underlying cause of BD is unknown. Major disease mechanisms in BD may be bacterial antigens with cross-reactivity to human peptides, genetic influences including association with certain 
human leukocyte antigens, altered populations of hematopoietic cells and associated cytokines, and/or the presence of immune complexes and autoantibodies [2]. Direct infection of affected tissues has not been observed, but certain viral and bacterial antigens that have cross-reactivity with human peptides may play a pathogenic role.

Long-term, low-dose treatment with CAM is widely used for the treatment of various lung disorders, including diffuse panbronchiolitis, cystic fibrosis, persistent chronic rhinosinusitis, nasal polyposis, bronchiectasis, asthma and cryptogenic organizing pneumonia [4]. The mechanism of these CAM actions has not been fully explored. It is thought to be due to immune-modifying effects rather than to direct antimicrobial activity. Many immune-modifying effects have been reported [5], and low-dose CAM plays an important role in CD4(+) T cell responses in particular [6]. Moreover, it is suggested that long-term treatment with CAM is effective in the management of Crohn's disease [7].

In this reported case, bacterial pneumonia gradually worsened. Long-term, low-dose treatment with CAM was administered for the recurrence of pneumonia. For several years after this CAM treatment, symptoms of pneumonia, such as hemoptysis and secretion, improved, but about 5 years after the start of this medication, bacterial pneumonia gradually worsened. Until the CAM treatment, discrete ulceration of the terminal ileum and oral aphthous ulcers frequently relapsed once or twice per year. Upon CAM treatment, by total colonoscopy once or twice a year the discrete ulceration of the terminal ileum and oral aphthous ulcers were never revealed. During this treatment, 5-ASA treatment was continued without glucocorticoids. This clinical course suggests that long-term, low-dose treatment with CAM might have had clinical benefits for this patient. Immune-modifying effects of longterm, low-dose treatment with CAM could have played a role in inducing remission of intestinal BD.

Treatment with glucocorticoid should be generally applied in patients with extensive and severe intestinal BD. Recently, several reports have suggested that successful treatment of this disease was achieved with glucocorticoids plus azathioprine or infliximab [8]. Glucocorticoids plus azathioprine have been proven to be effective, but these medicines are limited because of their poor tolerability or potential for toxicity [9]. Infliximab is also very expensive. Long-term, low-dose treatment with CAM has few adverse effects, and this medical treatment is not so expensive. We recommend long-term, low-dose treatment with CAM as an alternative in the management of intestinal BD, especially in patients for whom steroid and/or azathioprine use is contraindicated.

In conclusion, we describe a patient with intestinal BD who was successfully treated with long-term, low-dose CAM. Further studies are warranted since no reports have described the effectiveness of this treatment in patients with intestinal BD.

\section{Disclosure Statement}

The author states that he has no conflict of interest. 
Hakozaki et al.: Effective Treatment of Intestinal Behçet's Disease with Long-Term, Low-Dose Clarithromycin

\section{References}

1 Lee SK, Kim BK, Kim TI, et al: Differential diagnosis of intestinal Behçet's disease and Crohn's disease by colonoscopy findings. Endoscopy 2009;41:9-16.

2 Direskeneli H: Behçet's disease: infectious aetiology, new autoantigens, and HLA-B51. Ann Rheum Dis 2001;60:996-1002.

3 Hatemi G, Silman A, Bang D, et al: EULAR recommendation for the management of Behçet's disease. Ann Rheum Dis 2008;67:1656-1662.

4 Crosbie PA, Woodhead MA: Long-term macrolide therapy in chronic inflammatory airway diseases. Eur Respir J 2009;33:171-181.

-5 Shinkai M, Henke MO, Rubin BK: Macrolide antibiotics as immunomodulatory medications: proposed mechanisms of action. Pharmacol Ther 2008;117:393-405.

6 Ding FM, Zhu SL, Shen C, Jiang YQ: Low-dose clarithromycin therapy modulates CD4(+) T-cell responses in a mouse model of chronic Pseudomonas aeruginosa lung infection. Respirology 2012;17:727-734.

7 Leiper K, Morris AI, Rhodes JM: Open label trial of oral clarithromycin in active Crohn's disease. Aliment Pharmacol Ther 2000;14:801-806.

8 Naganuma M, Sakuraba A, Hisamatsu T, et al: Efficacy of infliximab for induction and maintenance of remission in intestinal Behçet's disease. Inflamm Bowel Dis 2008;14:1259-1264.

$\checkmark 9$ Hirohata S: Is the long-term use of systemic corticosteroids beneficial in the management of Behçet's syndrome? Nat Clin Pract Rheumatol 2006;2:358-359.

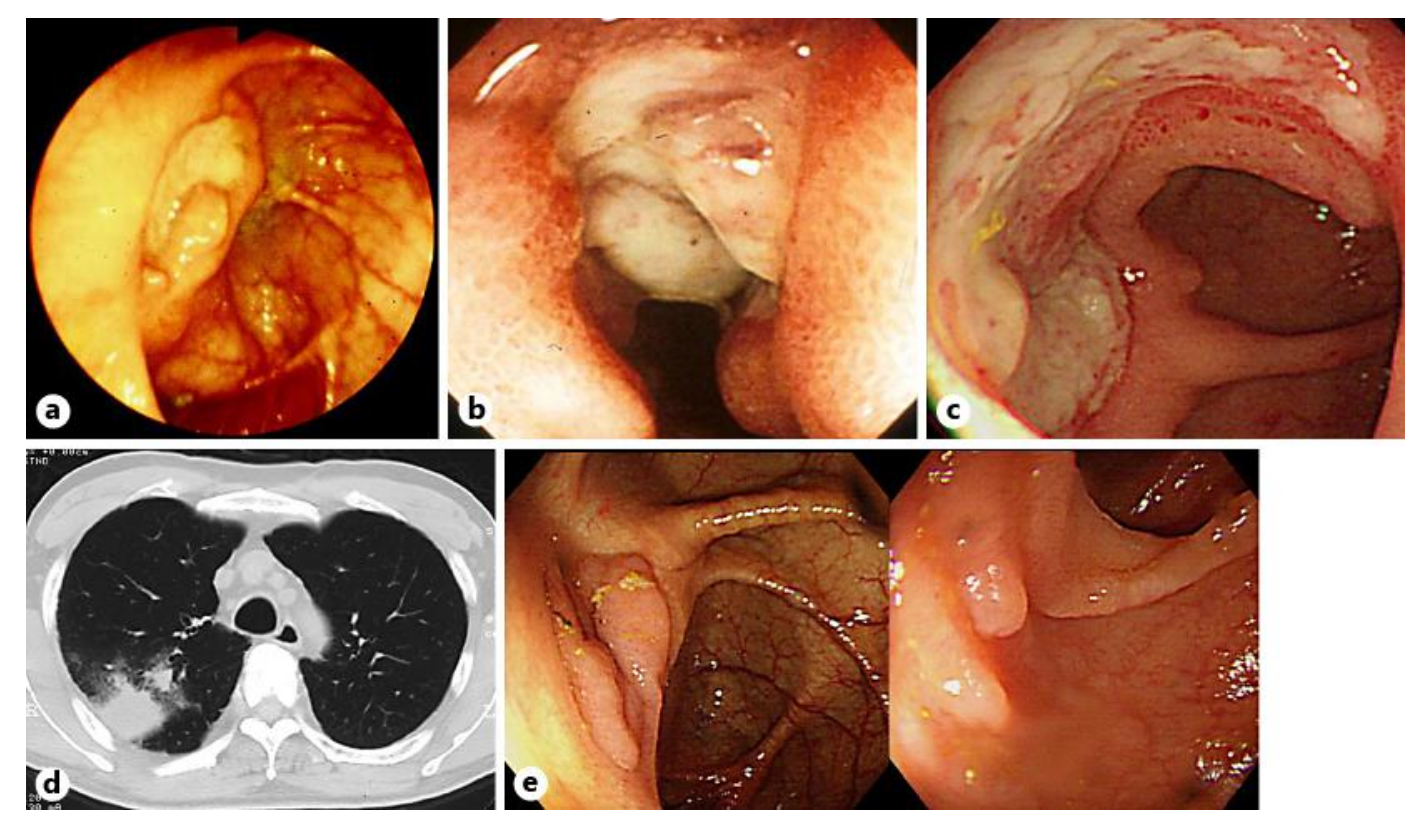

Fig. 1. a A discrete ulceration at the ileocecal valve in August 1989. b A deep discrete ulceration at the terminal ileum in October 1996. c A large ulceration at the ileum end in November 2003. d Chest CT showed irregular consolidation and ground-glass opacity in March 2003. e An ulcer scar at the ileocecal valve and ileum end in December 2006. 


\section{Case Reports in \\ Gastroenterology}

\begin{tabular}{l|l}
\hline Case Rep Gastroenterol 2013;7:122-126 \\
\hline DOI: $\underline{10.1159 / 000350320}$ & $\begin{array}{l}\text { @ 2013 S. Karger AG, Basel } \\
\text { www.karger.com/crg }\end{array}$ \\
\hline
\end{tabular}

Hakozaki et al.: Effective Treatment of Intestinal Behçet's Disease with Long-Term, Low-Dose Clarithromycin

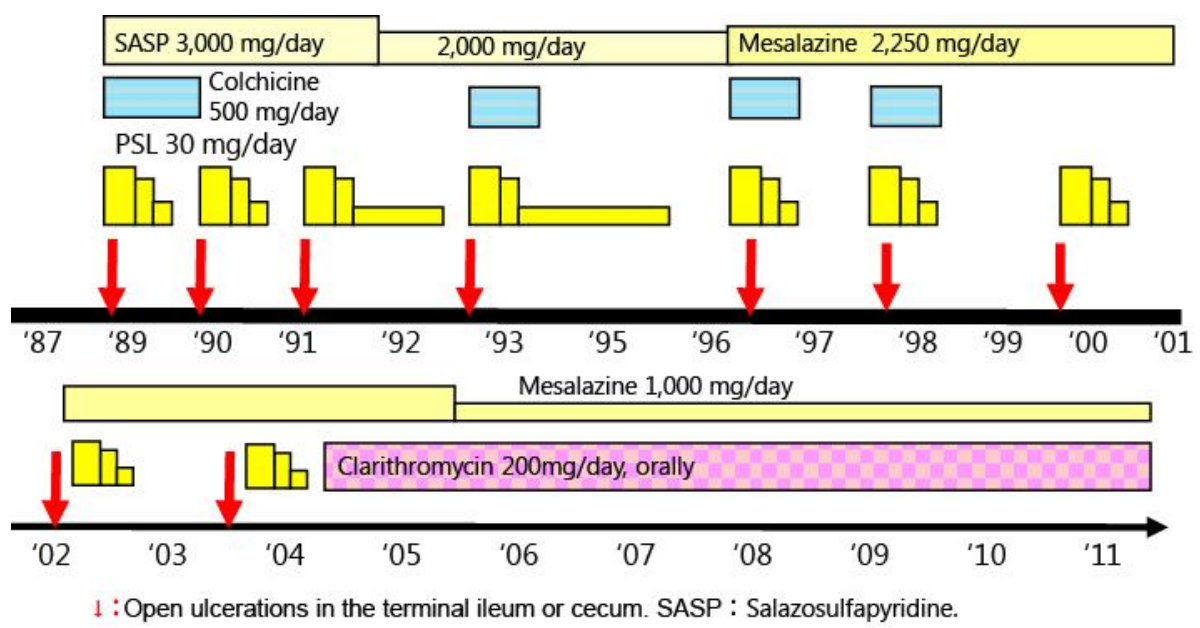

Fig. 2. Clinical course. In 2004, low-dose treatment with CAM was started. During this treatment with CAM, the discrete ulceration of the terminal ileum was never revealed by follow-up total colonoscopy once or twice per year for 7 years. 